\title{
FLOWER, HARRIET. THE DANCING LARES AND THE SERPENT IN THE GARDEN: RELIGION AT THE ROMAN STREET CORNER. PRINCETON: PRINCETON UNIVERSITY PRESS, 2017. 416 P. ISBN: 0691175004
}

\author{
Jonathan da Cruz Moreira ${ }^{1}$
}

Em sua mais recente obra, Harriet I. Flower se dedica ao estudo dos lares, divindades representadas geralmente em clima de festa, aos pares; dançando com suas túnicas curtas e com o rhyton despejando o vinho. $\mathrm{O}$ culto a estes alegres protetores dos lugares serve de pano de fundo, neste livro, para uma instigante investigação sobre o senso de comunidade no interior dos grupos subalternos romanos, com a prática religiosa como importante suporte.

Harriet I. Flower é graduada em história antiga e literatura clássica na Universidade de Oxford (1983) e pós-graduada na Universidade da Pennsylvania (1993); leciona antiguidade clássica desde 2003 na Mathey College Princeton University. Suas publicações se concentram nas áreas de religião, cultura e memória na Roma antiga, tendo publicado obras como Ancestor Masks and Aristocratic Power in Roman Culture (Oxford, 1996), The Art of Forgetting: Disgrace and Oblivion in Roman Political Culture (Chapel Hill, 2006), e Roman Republics (Princeton, 2010).

Segundo Flower, este livro tem como objetivo compreender a religião como parte integral e onipresente da vida comum romana aos níveis mais básicos, em especial para os grupos subalternos, os escravos, os libertos, homens ou mulheres. Para isso, Flower discute as diferentes formas nas quais os lares, definidos como deuses dos lugares, foram representados e cultuados em diferentes locais e temporalidades. Absolutos nas vidas dos cidadãos comuns, os lares faziam parte dos rituais de passagem, como casamentos, ou da transição à vida adulta; e protegiam a casa, a vizinhança, as muralhas da cidade ou as fronteiras das fazendas.

Em suas mais de 430 páginas, a obra está dividida em 4 partes, subdivididas em 7 a 10 capítulos. Com linguagem clara e de leitura fácil,

\footnotetext{
${ }^{1}$ Mestre em História pela Universidade Federal de São Paulo, São Paulo, Brasil. E-mail: jonathan.cruzmoreira@gmail.com
}

Heródoto, Unifesp, Guarulhos, v.4, n.1 - 2019.1. p. 427-432

DOI: 10.34024/herodoto.2019.v4.10132 
todos os capítulos são concluídos com um resumo objetivo dos temas propostos e discutidos, utilizando vasta e variada documentação. As fontes acerca das práticas religiosas populares são esparsas no tempo e no espaço, o que pede um cuidado especial. Em Lares and the Serpent in the Garden, no entanto, Harriet I. Flower coloca cada tipologia específica de fonte em sua própria perspectiva, respeitando suas especificidades. Poemas, tratados, peças de teatro, historiografia antiga, são contrastados de forma meticulosa com a iconografia religiosa e práticas que podem ser discernidas na linguagem visual encontrada principalmente nos sítios de Pompéia e de Delos. A abordagem comparativa entre espaços de influência romana permite observar como este culto tão romano conseguia adaptar-se às características das comunidades locais.

Na primeira parte, Lar(es)/ Genius and Juno/ Snake(s), a autora se dedica ao debate sobre a natureza destas divindades. Vários autores desde os dias de Cícero já colocavam em discussão a verdadeira origem dos lares, tendo suas vozes ecoadas em trabalhos modernos. Seriam eles, deuses do submundo ou espíritos dos antepassados cujo culto pacificava o mundo dos mortos e dos vivos? Flower discorda frontalmente destas concepções. Baseando-se na contradição entre as diferentes hipóteses dos letrados antigos para a gênese e a essência dos lares, a autora defende uma distinção clara entre os lares e outros deuses e espíritos de proteção presentes nas casas romanas, tais como manes, penates ou o genius. Flower argumenta que tanto as práticas quanto a iconografia relacionada aos lares em nada permite associar estas alegres divindades dançantes com o submundo ou com os mortos: Os autores, sempre oriundos das elites, pouco sabiam a respeito de práticas religiosas mais próximas da cozinha.

Por vezes, os lares eram referidos na historiografia antiga e na literatura no singular, outras, no plural, enquanto na iconografia tanto da baía de Nápoles quanto em Delos, costumavam ser retratados em pares, identificados estreitamente como deuses protetores dos espaços. A peça de Plauto, Aulularia, retrata bem esta característica. Encenada pela primeira vez por volta de 195 a.C, a peça analisada pela autora traz o lar familiaris apresentando a si mesmo como protetor dos moradores e dos bens a ele confiados. Antes do crescimento vertiginoso da urbs, quando as casas possuíam menos divisões, um único focus dava luz e calor à casa e nele os lares eram adorados (a autora destaca a dificuldade em se determinar por certo como se dava este culto, se com imagens ou pinturas atrás da chama). Uma vez que muitas casas ganham outras dimensões e novos cômodos com funções específicas, o culto dos lares muda-se para a cozinha, acompanhando o lugar dos escravos encarregados da preparação do alimento e, também, de cultuar estes deuses protetores. 
Fora das casas, o compitum era o altar dos lares protetores do bairro, os lares compitales. Tanto no ambiente doméstico quanto no ambiente urbano, o sítio de Pompéia oferece ainda hoje oportunidades excepcionais de estudo da iconografia e da disposição dos objetos e locais de culto no espaço. Ainda nesta primeira etapa, a autora se dedica a uma leitura cuidadosa dos altares domésticos dedicados aos lares em Pompeia, na maior parte das vezes na cozinha e nos compita encontrados in situ, sempre em locais de cruzamento entre duas ou três ruas, geralmente próximos a fontes. A disposição da iconografia fortemente padronizada, permite analisar os elementos principais do ritual: figuras humanas com o porco trazido ao sacrifício ( representado às vezes apenas em cortes suínos), a flauta que dá a música, o gênio do pai de família e os próprios lares despejando o vinho; além da serpente, aparentemente exclusiva da bacia de Nápoles, que sai da seu ambiente natural, o jardim, para participar do sacrifício.

Já a segunda parte, Shrines for Lares in Rome, explora com mais detalhes os espaços sagrados dedicados aos lares. Em Roma, grandes templos vinculados à religião oficial foram erigidos em honra aos lares, como o dos Lares Permarini, como agradecimento pela vitória marítima sobre o rei Selêucida Antíoco III; na via sacra, o templo dos lares in summa sacra via teria um culto ainda mais antigo, vinculado à proteção do território romano. Mar e terra eram, nesses templos (aedes), protegidos pelos lares. Em santuários menores, como os ara, sacellum e fanum, outros lares nomeados eram reverenciados, cada qual com sua função protetora própria; alguns deles, como os lares quaerquetulani e grundiles, são quase inacessíveis a nós dada a escassez de referências, mas possuem parentesco próximo com a mitologia entorno da fundação da cidade. Os lares praestites, por sua vez, têm sua iconografia preservada em um denário de 112 a.C, de L. Caesius, trazendo no anverso dois deuses em pé com seu cão de guarda, preparados para defender as muralhas da cidade.

Estes lares nomeados cultuados em seus santuários pela cidade, segundo a autora, não devem ser confundidos com os lares compitales ou os lares familiares, cuja impessoalidade de seus nomes reflete a missão de proteção da comunidade como um todo. A eles se dedicam as passagens da vida adulta, como por exemplo, o casamento. A noiva trazia consigo uma moeda para o noivo, simbolicamente comprando seu espaço na nova casa, uma moeda para o lar familiaris, pedindo licença ao protetor da casa e, por fim, aos lares compitales mais próximos, simbolicamente sacramentando sua posição como recém-chegada na comunidade sob sua proteção. Ainda sobre os compita, a autora retorna ao espaço urbano de Pompéia para um estudo das disposições destes altares na cidade. Sua proximidade com 
fontes d'água e sua posição central nos vici fazia do compitum um ponto de encontro, formando em seu entorno uma comunidade orgânica.

A terceira parte, Celebrating Lares, concentra-se na análise das práticas de culto e das associações formadas entre os grupos populares em Roma e fora dela com o objetivo de cultuar os lares. A principal festividade que envolvia o culto aos lares e que mobilizava os magistrados da comunidade era a Compitalia. A compitalia era celebrada nos altares das encruzilhadas dedicados aos lares em datas variáveis, geralmente coincidindo com o fim de dezembro e início de janeiro. Neste dia, os lares compitales eram homenageados com bolos de mel oferecidos por cada casa, guirlandas nos compita, muito vinho e a carne do porco que era sacrificado em seu altar. Para a autora, a tradição de se pendurar nos altares bonecas de lã (representando os livres e libertos da comunidade) e bolas de lã (representando os escravos), permitia saber exatamente quantos indivíduos pertenciam à comunidade local e seu status. Cada vicus organizava-se entorno de seus magistrados, os vicomagistri (em Roma, geralmente libertos), assistidos pelos ministri (frequentemente escravos), que eram as figuras centrais nas celebrações.

No mesmo espaço haviam os collegia, associações que uniam indivíduos pertencentes a um mesmo culto ou a uma mesma atividade comercial ou profissional. Para Flower, a participação dos collegia nos eventos da compitalia era relacionada sobretudo aos jogos que ocorriam durante as festas, os ludi compitalici, e não à festividade em si. Segundo a autora, teriam sido proibidos em 64 a.C. por seu envolvimento em supostos movimentos políticos.

Ainda nesta terceira parte, a autora nos traz o caso de estudo de Delos. A cidade Helenística de Delos recebia entre os séculos II e I a.C uma grande quantidade de mercadores de todos os cantos da Itália e, com eles, seus escravos. Esta comunidade de influência Italiana formava-se mantendo algumas de suas tradições, entre elas o culto aos lares e a festa da compitalia, como retratado nos afrescos do sítio de Delos analisados pela autora e as inscrições mostrando a existência de um grupo formado entre libertos e escravos para a promoção da compitalia, os kompetaliastai. Mesmo sem compita delimitando o espaço urbano, os lares estavam nas cozinhas e a compitalia era festejada, demonstrando como estas divindades ligadas à comunidade eram adaptadas de acordo com as características locais.

Por fim, a quarta parte Augustus and Lares, se concentra nas reformas religiosas empreendidas no decorrer das primeiras décadas do governo de Augusto, à medida que se consolidava como o maior poder sobre Roma a caminho do principado. Desde antes da introdução dos lares augusti, o

Heródoto, Unifesp, Guarulhos, v.4, n.1 - 2019.1. p. 427-432

DOI: 10.34024/herodoto.2019.v4.10132 
primeiro imperador doava pequenas imagens de lares, os lares publici, a serem cultuadas no âmbito das comunidades locais, pagos com os valores arrecadados a partir de presentes (stips) que recebia da plebe romana no ano novo. A partir de 7 a.C., juntamente com a reforma que dividia a cidade em 14 regiones, estas, subdivididas em vici administrados pelos vicomagistri, reviveu os ludi compitalici, além de introduzir os lares augusti. Neste ponto, a autora reflete sobre a natureza teológica dos lares augusti, descritos frequentemente pela historiografia como um culto ao gênio de Augusto ou então a extensão do culto doméstico dos lares de Augusto e sua casa, aos altares nas encruzilhadas.

Para Flower, não há evidências que possam relacionar o culto aos lares augusti introduzido em 7 a.C., ao gênio de Augusto e a distinção entre o gênio e os lares é feita de forma bastante clara já na primeira parte da obra. Em segundo lugar, o lar não pode deixar o altar doméstico e habitar outro lugar. Lançar os lares de casa para fora era, inclusive, um sinal de desespero. As reformas de Augusto aproximavam o imperador e a plebe romana nos aspectos mais sutis e pessoais da comunidade, que passa a contar os anos nas dedicatórias dos altares partindo das reformas dos vici, iniciando uma nova era.

The Dancing Lares and the Serpent in the Garden: Religion at the Roman Street Corner convida o leitor a conhecer um mundo que foi frequentemente eclipsado tanto pela historiografia moderna quanto pela literatura antiga, o mundo dos romanos comuns, apresentando o culto aos lares como parte integrante de uma religiosidade tradicional que não dependia dos grandes templos e complexas narrativas mitológicas, mas que eram, sim, profundamente ligada a um senso de comunidade e de pertencimento que permitia também a variedade de representações e de performances religiosas entre os três locais nos quais os estudos se concentraram: Roma, Delos e Pompéia. Talvez a principal crítica que caiba ao trabalho esteja justamente na ausência de uma perspectiva comparativa para além destes três estudos de caso. Fica sem resposta a pergunta sobre como (e se) os lares eram cultuados em outras províncias romanas, o que é perfeitamente justificado pelo escopo do projeto, manifestamente interessado nas práticas religiosas da urbs. Trata-se de uma obra detalhada, de leitura fácil e fluída e corajosa, que sem dúvida contribui tanto para o estudo da religiosidade romana tardo-republicana e nos tempos de Augusto, como também, para os estudos dos grupos subalternos do mundo romano de modo geral. 
Referências bibliográficas

FLOWER, Harriet. The dancing Lares and the serpent in the garden: religion at the Roman street corner. Princeton: Princeton University Press, 2017. 